\title{
Disruption of the carA gene in Pseudomonas syringae results in reduced fitness and alters motility
}

(1) CrossMark

Bronwyn G. Butcher ${ }^{1,4}$, Suma Chakravarthy ${ }^{1}$, Katherine D'Amico ${ }^{1,2}$, Kari Brossard Stoos ${ }^{3}$ and Melanie J. Filiatrault ${ }^{1,2^{*}}$

\begin{abstract}
Background: Pseudomonas syringae infects diverse plant species and is widely used in the study of effector function and the molecular basis of disease. Although the relationship between bacterial metabolism, nutrient acquisition and virulence has attracted increasing attention in bacterial pathology, there is limited knowledge regarding these studies in Pseudomonas syringae. The aim of this study was to investigate the function of the carA gene and the small RNA P32, and characterize the regulation of these transcripts.
\end{abstract}

Results: Disruption of the carA gene ( $\triangle$ carA) which encodes the predicted small chain of carbamoylphosphate synthetase, resulted in arginine and pyrimidine auxotrophy in Pseudomonas syringae pv. tomato DC3000. Complementation with the wild type carA gene was able to restore growth to wild-type levels in minimal medium. Deletion of the small RNA P32, which resides immediately upstream of carA, did not result in arginine or pyrimidine auxotrophy. The expression of carA was influenced by the concentrations of both arginine and uracil in the medium. When tested for pathogenicity, $\triangle c a r A$ showed reduced fitness in tomato as well as Arabidopsis when compared to the wild-type strain. In contrast, mutation of the region encoding P32 had minimal effect in planta. $\triangle$ carA also exhibited reduced motility and increased biofilm formation, whereas disruption of P32 had no impact on motility or biofilm formation.

Conclusions: Our data show that carA plays an important role in providing arginine and uracil for growth of the bacteria and also influences other factors that are potentially important for growth and survival during infection. Although we find that the small RNA P32 and carA are co-transcribed, P32 does not play a role in the phenotypes that carA is required for, such as motility, cell attachment, and virulence. Additionally, our data suggests that pyrimidines may be limited in the apoplastic space of the plant host tomato.

Keywords: Pseudomonas syringae pv tomato, CarAB, P32, Virulence, Swarming, Biofilm formation

Abbreviations: CFU, Colony forming units; CPSase, Carbamoylphosphate synthetase; FLOE, Fluorescently labeled oligonucleotide extension; G6PDH, Glucose-6-phosphate dehydrogenase; HR, Hypersensitive response; IVET, In vivo expression technology; KB, King's B; MG, Mannitol-glutamate; APCR, Quantitative real-time PCR; RACE, Rapid amplification of CDNA ends; T3SS, The type III secretions system; VBMM, Vogel-bonner minimal medium

\footnotetext{
* Correspondence: Melanie.filiatrault@ars.usda.gov

${ }^{1}$ School of Integrative Plant Science, Section of Plant Pathology and

Plant-Microbe Biology, Cornell University, Ithaca, NY, USA

${ }^{2}$ Emerging Pests and Pathogens Research Unit, Robert W. Holley Center for

Agriculture and Health, Agricultural Research Service, United States

Department of Agriculture, Ithaca, NY, USA

Full list of author information is available at the end of the article
}

\section{Ciomed Central}

(c) 2016 The Author(s). Open Access This article is distributed under the terms of the Creative Commons Attribution 4.0 International License (http://creativecommons.org/licenses/by/4.0/), which permits unrestricted use, distribution, and reproduction in any medium, provided you give appropriate credit to the original author(s) and the source, provide a link to the Creative Commons license, and indicate if changes were made. The Creative Commons Public Domain Dedication waiver (http://creativecommons.org/publicdomain/zero/1.0/) applies to the data made available in this article, unless otherwise stated. 


\section{Background}

The model plant pathogen Pseudomonas syringae pv. tomato DC3000 (DC3000) infects tomato (Solanum lycopersicum) and Arabidopsis thaliana (reviewed in [1]). DC3000 enters the apoplastic space through wounds or natural openings in the leaf, like stomata, and grows in intercellular spaces. As the infection progresses, the pathogen releases virulence factors such as the phytotoxin coronatine and injects effector proteins into host cells through the type III secretions system (T3SS). In a susceptible host, chlorosis (yellowing) of the leaves occurs and necrotic lesions develop. Alternatively in a non-host, such as Nicotiana benthamiana, a defenseassociated hypersensitive response (HR) is elicited.

Most investigations of pathogenicity in $P$. syringae have focused on identifying and characterizing components of the T3SS [2], non-ribosomal peptides [3] and toxins $[4,5]$. While these are clearly important, pathogenic bacteria must also compete successfully for limited nutrients within the host, with iron as a well-known example [6]. Unfortunately, it is not well-understood how metabolic processes in plant pathogens contribute to virulence, although experiments using IVET (in vivo expression technology) have identified a variety of bacterial genes expressed during plant-pathogen interactions as well as during host colonization [7-15]. These studies revealed the importance of genes involved in metabolism to the infection process.

Several lines of evidence suggest links between bacterial pathogenicity and metabolism. The disruption of genes involved in acquisition of nutrients such as carbon result in reduced virulence in human and animal pathogens [16-21]. As for plant pathogens, a number of metabolically related genes were identified as required for infection of shoots of apple trees by Erwinia amylovora [22] and it was shown that P. savastanoi pv savastanoi requires genes directly involved in metabolism in order to survive in olive knots [23]. Arginine metabolism and regulation are associated with the virulence of several pathogenic bacteria such as Mycobacterium tuberculosis, Listeria monocytogenes, Legionella pneumophila, and Mycobacterium bovis [24-27]. Recently Ramos et al. showed that an $\arg D$ mutant in the plant pathogen Erwinia amylovora was non-pathogenic [28].

Our laboratory is interested in the identification and characterization of small RNAs in P. syringae. Livny et al. reported a Pseudomonas-specific small RNA (named P32) transcribed from an orthologous region upstream from the carABgreA operon in Pseudomonas aeruginosa [29]. The expression of P32 was confirmed by Northern blot and a transcript of about 80 bases was detected in rich medium during exponential growth and stationary phase cultures. No other function has been described for this regulatory RNA. This region is also present in the genome of DC3000. While conducting a genome-wide mapping of mRNA 5 'ends in DC3000, we identified a potential transcriptional start site 118 bases upstream of $\operatorname{car} A$ [30]. The $\operatorname{car} A B$ genes encode the enzyme carbamoylphosphate synthetase (CPSase), which catalyzes the synthesis of carbamoylphosphate, a precursor of arginine and pyrimidines. Further analysis revealed a putative RpoD promoter a short distance upstream from the start site, as well as a potential rhoindependent terminator located between the start site and the first codon of $\operatorname{car} A$. The promoter may be associated with two overlapping transcripts, a shorter one utilizing the Rho-independent terminator, and a longer one that includes $\operatorname{car} A$, carB, and greA (pseudomonas.com). Consistent with this model, we observed expression in the region encompassing the $5^{\prime} \mathrm{UTR}, \operatorname{car} A, \operatorname{car} B$, and gre $A$ in a transcriptome analysis of the DC3000 genome [31] and detected transcriptional activity in the same region during a search for small RNAs using RNASeq (unpublished). Regulation of the carABgreA operon in $P$. aeruginosa is controlled both by arginine at the transcriptional level and also by pyrimidines, possibly through an attenuation mechanism [32, 33]. $\operatorname{car} A B$ mutants of Pseudomonas spp. strain G are auxotrophic for arginine as well as pyrimidines [34]. In addition, these mutants are deficient in extracellular polysaccharide production. The function of carbamoyl-phosphate synthase and P32 has not been well characterized in plant pathogenic bacteria. Just recently it was demonstrated that disruption of carB in Xanthomonas citri, resulted in loss of pathogenicity and inability to elicit a hypersensitive reaction in non-hosts, whereas disruption of carA did not affect these phenotypes [35]. However, disruption of $c a r B$ resulted in reduced swimming and reduced ability to form biofilms [36].

The regulation of $P 32$ as well as $\operatorname{car} A B$ and their potential contribution to virulence has not been investigated in $P$. syringae. In this study, we investigated P32 and its involvement in the regulation of carA in $P$. syringae. We found that carA is important for growth and fitness in planta and demonstrated the likely importance of uracil during infection. In contrast, P32 appears to be involved in carA regulation and does not have an obvious role in planta, although P32 is part of the same transcriptional unit as $\operatorname{car} A$.

\section{Results}

\section{Effect of P32 and carA deletions on growth of DC3000}

In previous work, a MEME analysis of DC3000 genomic regions immediately upstream from captured RNA 5' ends revealed a candidate $\mathrm{RpoD}$ promoter adjacent to the putative small RNA P32 [30]. P32 is located immediately upstream of PSPTO_4502 (carA) (Fig. 1). In other organisms the products of $\operatorname{car} A$ and $\operatorname{car} B$ are involved in 


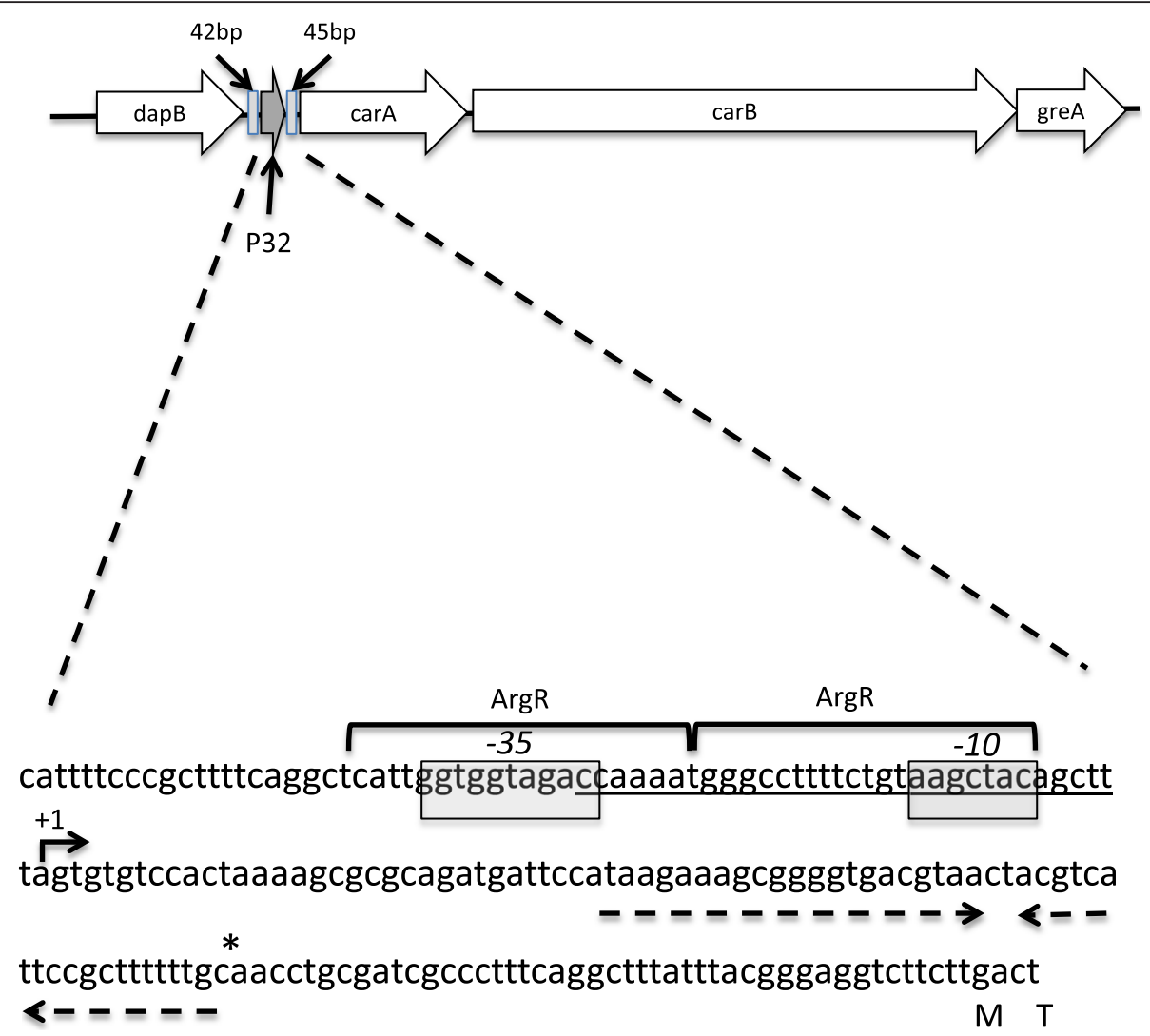

Fig. 1 Genomic sequence of the genomic region containing P32. The transcriptional start site (reported in Filiatrault et al., 2011) is denoted with an arrow and marked as +1 . The putative RpoD-dependent promoter sequence (MEME motif 1;[30]) is underlined. Boxed areas represent the -35 and -10 sites. The ArgR binding sites reported for Pseudomonas aeruginosa [42] consisting of two half sites in direct repeat arrangement, is indicated by brackets. A predicted terminator and inverted repeat is denoted by the convergent arrows. The mapped 3' end is denoted by the asterisk. The " $\mathrm{M}$ " represents the methionine start codon for CarA and " $T$ " is the symbol for the amino acid threonine. 42 bp denotes the base pairs between the end of the coding region of DapB and the putative ArgR binding site. 45 bp denotes the base pairs from the mapped $3^{\prime}$ end of P32 to the translational start site of CarA

the biosynthesis of arginine and pyrimidines [37] and carA mutants have been shown to require arginine for optimal growth [38-41]. We hypothesized that P32 may also be involved in these pathways since it closely neighbors carA. To test the involvement of P32 and CarA in arginine and pyrimidine biosynthesis we constructed two deletion mutants, one in which P32 was deleted and another in which carA was deleted. Deletions were confirmed by PCR and sequencing (data not shown). The transcript for carA could still be detected in the P32 deletion mutant indicating transcription of carA can occur in the absence of the genomic region containing P32 (Additional file 1: Figure S1). Growth of the P32 deletion mutant was comparable to that of the wildtype strain DC3000 in rich medium KB, minimal medium MG, and minimal medium VBMM (Fig. 2). In contrast, the carA mutant displayed a growth defect when grown in rich medium, and minimal media MG and VBMM. The growth defect was abolished by the simultaneous addition of arginine and uracil to VBMM.
Also, complementation of the carA mutant by expressing the coding region of carA on a plasmid, restored growth to wild type levels (Additional file 1: Figure S2), indicating that the carA gene was solely responsible for the phenotype observed. Overall the data suggests that P32 is not required for expression of carA and that carA is involved in metabolism of arginine and uracil.

\section{Expression of $P 32$ and carA in DC3000}

In $P$. aeruginosa, the expression of car $A$ is controlled by both pyrimidines and arginine [32,33]. To investigate if $P 32$ influences the expression of carA in P. syringae, we performed a series of transcriptional analyses. First, to confirm transcriptional activity and to verify the $3^{\prime}$ end of P32 we performed 3' RACE. A 3' end was identified at nucleotide position $5073275 \mathrm{c}$, immediately downstream from the predicted Rho-independent terminator (Fig. 1). The presence of a 3 'end in this region could occur as a result of several events. One possibility is that distinct promoters produce two separate transcripts, one 
KB

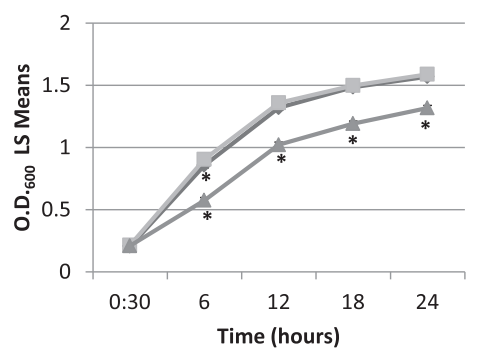

VBMM

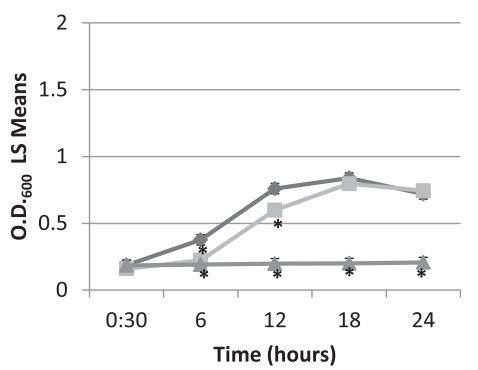

VBMM + Uracil

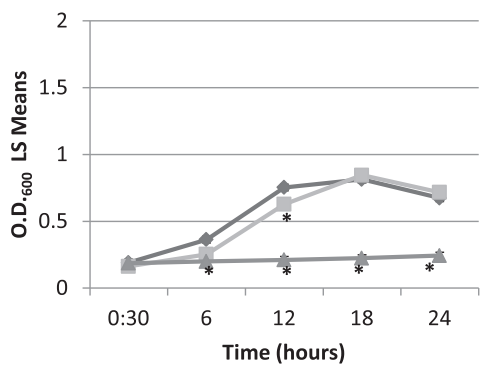

MG

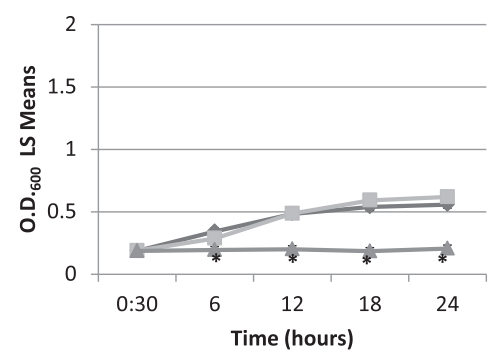

VBMM + Arginine

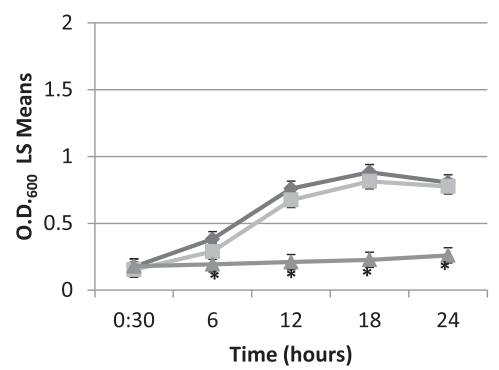

VBMM + Arginine + Uracil

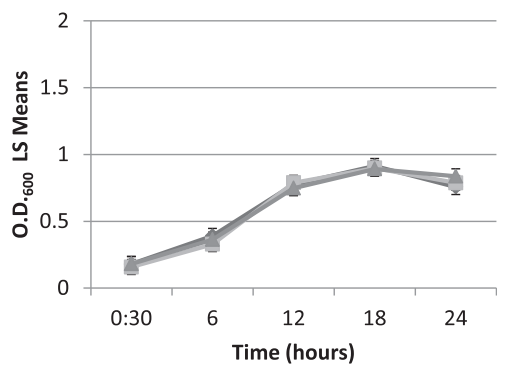

Fig. 2 CarA influences growth in minimal medium. Growth of wild type DC3000 (dark gray diamonds), $\triangle$ P32 (light gray squares) and $\triangle$ carA (light grey triangles) in KB, MG, VBMM, VBMM supplemented with $40 \mathrm{mM}$ arginine or with $10 \mathrm{mM}$ uracil, and VBMM supplemented with 40 mM arginine and $10 \mathrm{mM}$ uracil. Growth is represented as least squares means with standard error of O.D.600 over time. The data shown represent three biological replicates per strain, each with three technical replicates. Post hoc comparisons were performed using Tukey HSD ( $a=0.05)$. For each time point, the values which are significantly different from the wild type are shown with an asterisk. Statistical analyses were performed using JMP Pro 11

containing P32 and another containing carA, carB, and gre $A$. Alternatively a transcript could arise from a single transcriptional start site, but under certain conditions termination or cleavage/processing could result in the generation of a small transcript containing P32 alone. Our 5 'end mapping data did not detect another transcriptional start site for carA [30] although our transciptome survey detected expression through the entire P32-carA-carB-greA operon [31]. A second 5' mapping experiment using fluorescently labeled oligonucleotide extension (FLOE) detected a single transcriptional start site using RNA isolated from cells grown in VBMM and VBMM supplemented with arginine and uracil (data not shown). This suggests that expression of the entire P32-carA region may be under the control of a single promoter, as is the case in $P$. aeruginosa [32, 33].
To investigate if $P 32$ is co-transcribed with carA, RNA was isolated from cells grown under rich or growthlimiting conditions. cDNA synthesis was performed and used for bridging PCR with different primer pairs to identify RNA that consists of both P32 and carA (see Fig. 3a). Products were obtained with each primer set using RNA from bacteria grown with or without arginine and uracil (Fig. 3b). This suggests that P32 and carA are co-transcribed under the conditions tested. These data also indicate that carA is transcribed even in the presence of arginine and uracil.

To further investigate the regulation of $P 32$ and carA we created promoter fusions and evaluated their expression in the wild-type strain (Fig. 4, top panel). The promoter fusions consisted of either the entire intergenic region between dapB (PSPTO_4503) and carA, including P32 (referred to as P1), the region from the $3^{\prime}$ end 


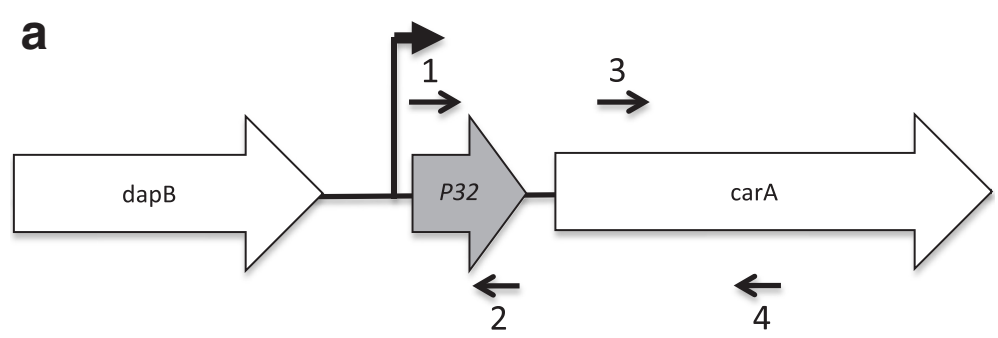

b

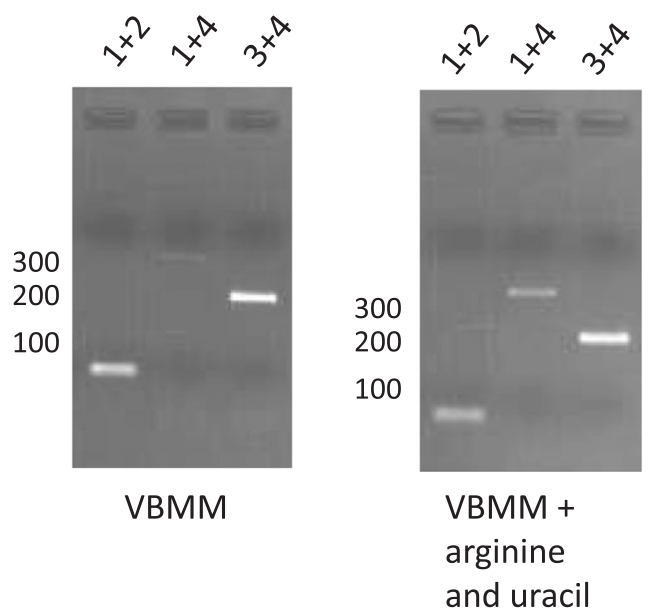

Fig. 3 Co-transcription of $P 32$ and carA. a Map of the genomic region containing dapB, P32 and carA in DC3000. The locations and orientations of RT- and PCR primers are indicated. $\mathbf{b}$ Agarose gel electrophoresis result of the RT-PCR experiments using the primers pairs indicated. The expected length of the PCR products for the primer pairs are as follows: Primer pair 1 and 2, 54 bps; primer pair 1 and 4 , 370 bps; and primer pair 3 and 4, 209 bps. Control reactions in which reverse transcriptase was omitted were performed for each primer set and RNA sample

of $\operatorname{dap} B$ to the first half of the Rho-independent terminator, which therefore lacks $1 / 2$ of the stem-loop (referred to as P3), the region from the 3 'end of $\operatorname{dapB}$ to the beginning of the stem-loop (lacks the entire stem-loop and all sequence downstream; referred to as P4), P32 and downstream sequences up to $\operatorname{car} A$ (lacks putative promoter sequence; referred to as $\mathrm{P} 5$ ), or the region between the $3^{\prime}$ end of P32 and carA (lacks putative promoter region and P32; P6). Fusions lacking the putative promoter region (P5 and P6) were expressed at background levels in VBMM or VBMM supplemented with arginine or uracil (Fig. 4). This is consistent with the single mapped transcriptional start site for carA and P32 and the co-expression data that indicates P32 and $\operatorname{car} A$ are transcribed together from a single promoter under these conditions. In addition, we observed an increase in expression when the stem-loop structure was disrupted (P3) or completely removed (P4) compared to the full-length fusion P1. We conclude that this feature is important in modulating the expression of carA.

Interestingly, when arginine was added to the medium we observed an increase in expression from promoter fusions P1, P3 and P4 (Fig. 4). The addition of uracil resulted in a decrease in expression of lux from the promoter fusions P1. The addition of both arginine and uracil had little effect on the expression of the promoter fusions.

To further investigate the expression of P32 and carA, qRT-PCR was performed with RNA isolated from wild-type cells grown in VBMM and VBMM supplemented with $40 \mathrm{mM}$ arginine and $10 \mathrm{mM}$ uracil. Although transcripts for P32 and carA were detected in both growth conditions, no difference in expression was observed between cells grown in VBMM or VBMM supplemented with arginine and uracil (data not shown). This is consistent with the promoter fusion data.

\section{ArgR regulates expression of $P 32$ and car $A$}

ArgR binds to a region upstream of $\operatorname{car} A$ in $P$. aeruginosa [33, 42]. Although ArgR can act as a repressor or activator, in $P$. aeruginosa it has been shown to act as a repressor of carA expression [42]. Because the predicted binding site for ArgR, TGTCGCN $\mathrm{AAN}_{5}$ appears to be conserved in $P$. syringae (Fig. 1), we hypothesized that ArgR would also regulate P32 and/ or carA in $P$. syringae. We analyzed the expression 

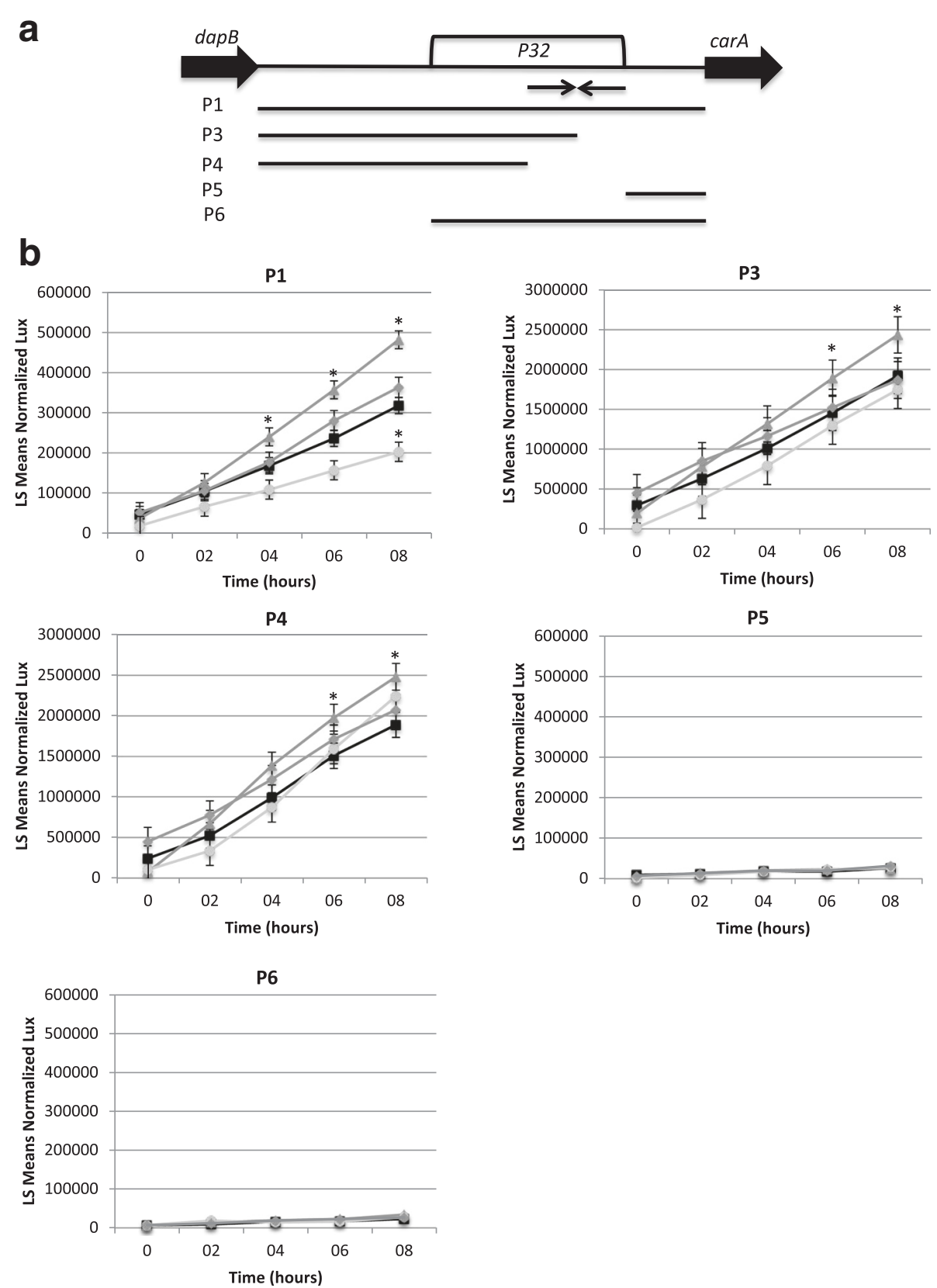

Fig. 4 Expression of $P 32$ and carA. a Regions of varying lengths upstream to the carA coding region were cloned into lux reporter constructs; the regions they span are shown graphically. The inverted arrows represent the predicted stem-loop of the Rho-independent terminator. (b) Expression from lux promoter fusions were evaluated in VBMM medium (black squares), VBMM supplemented with 40 mM arginine (dark gray triangles), VBMM supplemented with $10 \mathrm{mM}$ uracil (light gray circles), and VBMM supplemented with $40 \mathrm{mM}$ arginine and $10 \mathrm{mM}$ uracil (dark gray diamonds). Data shown are the least squares means (LS Means) with standard error of normalized luminescence (lux) values over time, derived from at least 3 independent biological replicates for each promoter fusion-medium combination, each containing 2-3 technical replicates. Note that the scales for each panel are different in order to clearly show statistically different data points. For each time point, the values which are significantly different from VBMM are shown with an asterisk (using Tukey HSD, $a=0.05$ ). Normalized luminescence (lux) is the ratio of luminescence to $\mathrm{OD}_{600}$. Statistical analysis was performed using the program JMP Pro11

levels of $P 32$ and carA in the $\triangle \operatorname{argR}$ mutant and wildtype DC3000 using qRT-PCR. Our results show that expression of $P 32$ is increased in the $\triangle \operatorname{argR}$ mutant compared to the wild-type strain at mid-log and stationary phases, while carA expression is increased during mid-log phase (Fig. 5). These observations indicate that ArgR likely acts as a repressor of P32 and carA in DC3000. 


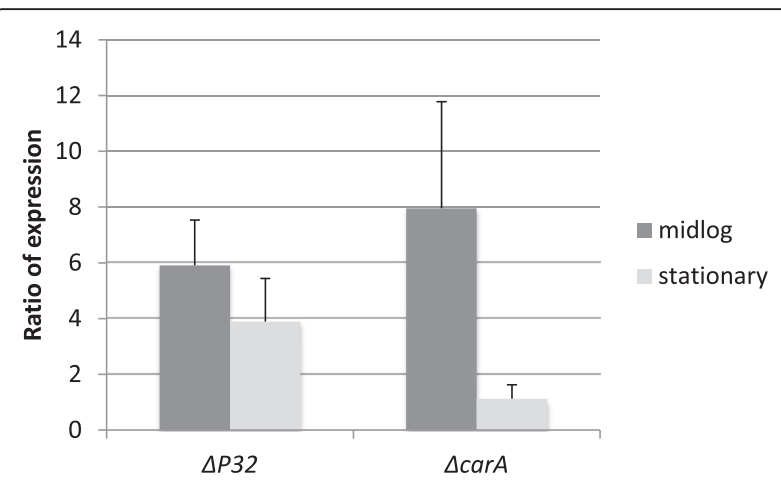

Fig. 5 Expression of $P 32$ and carA in wild-type DC3000 compared to $\triangle \arg R$ mutant using qRT-PCR. The dark gray bars represent the ratios of the transcripts comparing $\triangle$ argR mutant to the WT at mid-log phase, and the light gray bars represent the ratios of the transcripts comparing $\triangle a r g R$ mutant to the WT at stationary phase. RNA samples were normalized using gap1. The $\triangle \arg R$ mutant shows increased levels of P32 and carA transcript compared to the WT at mid-log phase. The levels of $P 32$ and carA transcripts were analyzed by calculating the fold difference of transcript levels between WT and $\triangle \arg R$ mutant using the $\Delta C_{t}$ method. Data shown are the average and standard deviation of three independent biological replicates

\section{Examining the contribution of $P 32$ and carA to virulence}

To test the involvement of P32 and CarA in virulence, tomato plants were dipped in suspensions of wild-type, $\triangle$ P32 mutant, and the $\triangle c a r A$ mutant. The $\triangle c a r A$ mutant displayed less intense disease symptoms and reduced bacterial growth on days 5 and 7 postinoculation compared to the wild type (Fig. 6). Although $\triangle P 32$ growth was similar to wild- type, it displayed reduced symptoms (Fig. 6). However, the symptoms caused by the $\triangle P 32$ mutant were more intense than $\triangle$ carA mutant.

Since the $\triangle$ carA mutant had reduced virulence in tomato, we tested the ability of this mutant and $\triangle P 32$ to cause disease in $A$. thaliana seedlings. $\triangle P 32$ grew to similar levels as the wild type (Fig. 7a). In addition, the chlorotic symptoms caused by $\triangle P 32$ were also similar to wild type (Fig. 7b). Based on these data, it is unlikely that $\triangle$ P32 plays a substantial role in virulence in DC3000. However, the $\triangle$ carA mutant displayed reduced growth and was not able to cause the same necrotic symptoms as the WT (Fig. 7a and b), suggesting that carA is necessary for growth and fitness in planta.

\section{Growth of $\triangle P 32$ and $\triangle$ carA in apoplastic fluid}

During infection, $P$. syringae obtains its nutrients from the apoplast. Therefore to investigate whether the observed reduction in growth in planta was due to nutrient limitation, we compared the growth of wild-type DC3000, $\triangle P 32$, and $\triangle c a r A$ in apoplastic fluid extracts. The wild-type strain and the $\triangle P 32$ mutant demonstrated similar growth. However, growth of $\triangle \operatorname{car} A$ was lower than the wild-type at earlier time points in apoplastic fluid with or without arginine. However, $\triangle$ carA was able to achieve growth levels similar to wild type at later time points (Fig. 8). In apoplastic fluid supplemented with uracil or both arginine and uracil, $\triangle$ carA and $\triangle P 32$ growth characteristics were similar to wild type, with no significant differences detected between the strains at all time points (Fig. 8).

\section{$\triangle$ car $A$ is reduced in motility}

The reduced virulence observed with the $\triangle c a r A$ mutant could be solely due to the inability to grow in vivo or the inability to produce other factors related to virulence. Because carA is induced in Salmonella cells that are swarming compared to cells that are in a vegetative state, and has been implicated in motility [43], we tested the ability of the $\triangle$ carA mutant to swarm. Since the $\triangle$ car $A$ mutant does not grow as efficiently as the wildtype strain in minimal media, the assay was conducted in nutrient agar, a rich medium that is used to test swarming of $P$. aeruginosa. All strains grew equally in this medium (data not shown). As shown in Fig. 9a, the wild-type strain, $\triangle \operatorname{argR}$ mutant and $\triangle P 32$ mutant swarmed equally (Fig. 9a) in this medium while the $\triangle$ carA mutant exhibited reduced swarming (ANOVA, $P$ value $<0.004$ and Tukey HSD, $P$-values $<0.01$ ) (Fig. 9a). Motility was also examined using a soft agar to test for functional flagella. The $\triangle$ carA mutant showed reduced swimming compared to the wild-type, $\triangle \operatorname{argR}$ mutant and $\triangle P 32$ mutant (ANOVA $P$-value $<0.002$; Tukey HSD $P$-value <0.05) (Fig. 9b).

\section{Deletion of carA affects cell attachment}

Since motility plays an important role in the ability of the bacteria to colonize different environments and attach to surfaces, we examined the $\Delta c a r A$ mutant using the microtiter dish assay that has become a standard tool for the study of the early stages in biofilm formation [44]. The $\triangle$ carA mutant showed a statistically significant $(P<0.003$ by ANOVA; $P<0.01$ using Tukey HSD) increase in biofilm formation in comparison to the wild type (Fig. 10). No observable growth differences were observed when the $\mathrm{OD}_{600}$ of planktonic cells was measured as a function of time during the period of growth in the microtiter wells.

\section{Discussion}

Although the $\operatorname{car} A B$ operon is conserved in many bacteria, its regulation is surprisingly variable. [37]. The well-characterized $c a r A B$ operon in E. coli (reviewed by [45]) is regulated by several mechanisms. This operon makes use of two tandem promoters that are separately regulated by pyrimidines and arginine. The more distal or upstream promoter is regulated by numerous factors 
a

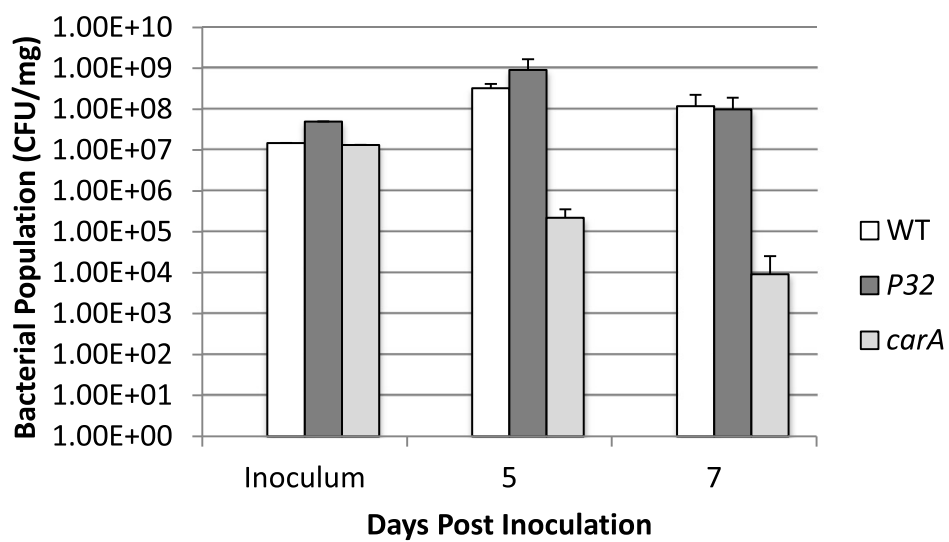

b

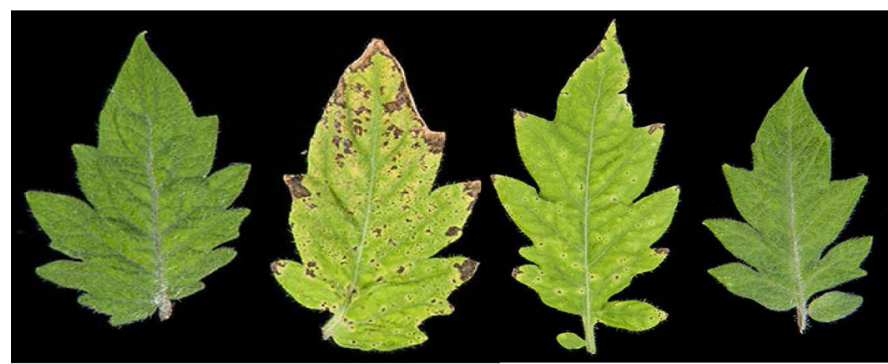

Mock

WT

$\triangle P 32$

$\Delta c a r A$

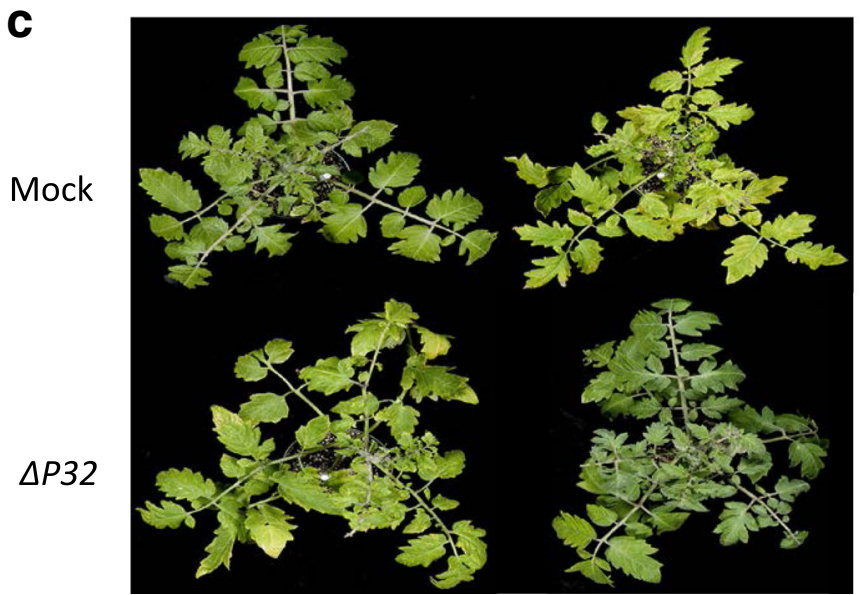

WT

$\Delta$ carA

Fig. 6 carA contributes to fitness in tomato. a Four-week-old Tomato cv. MoneyMaker tomato plants were dipped in suspensions containing $1 \times 10^{7} \mathrm{CFU} \mathrm{ml}{ }^{-1}$ of $\mathrm{WT}, \triangle \mathrm{P} 32$, or $\triangle \mathrm{car}$. At the time points indicated, bacteria were extracted from leaves and plated on $\mathrm{KB}$ containing rifampicin for enumeration. The values shown are the average CFU/mg with standard deviation from three plants per strain. Similar results were obtained in two repetitions of the experiment. b Tomato leaves photographed at $7 \mathrm{dpi}$ (c) Whole tomato plants photographed at $7 \mathrm{dpi}$

including integration host factor (IHF), the purine repressor (PurR), the pyrimidine ultilization regulator (RutR) as well as PepA, an aminopeptidase and a UMPkinase PyrH. Additional regulation occurs through reiterative transcription (or RNA polymerase stuttering) when dUTP is available at high concentration, nascent transcripts originating at this promoter are released prematurely due to RNA polymerase stuttering at a T-rich region immediately downstream from the transcriptional start site. The second (proximal) promoter is negatively regulated by the transcriptional regulator ArgR which consists of two trimers that are stabilized by the binding of arginine.

In contrast to E.coli, car $A B$ in $P$. aeruginosa is transcribed from a single promoter [32]. car $A B$ expression increases in response to limitation of either arginine or pyrimidine. The $c a r A B$ transcript includes an upstream untranslated region (UTR) that contains a potential 

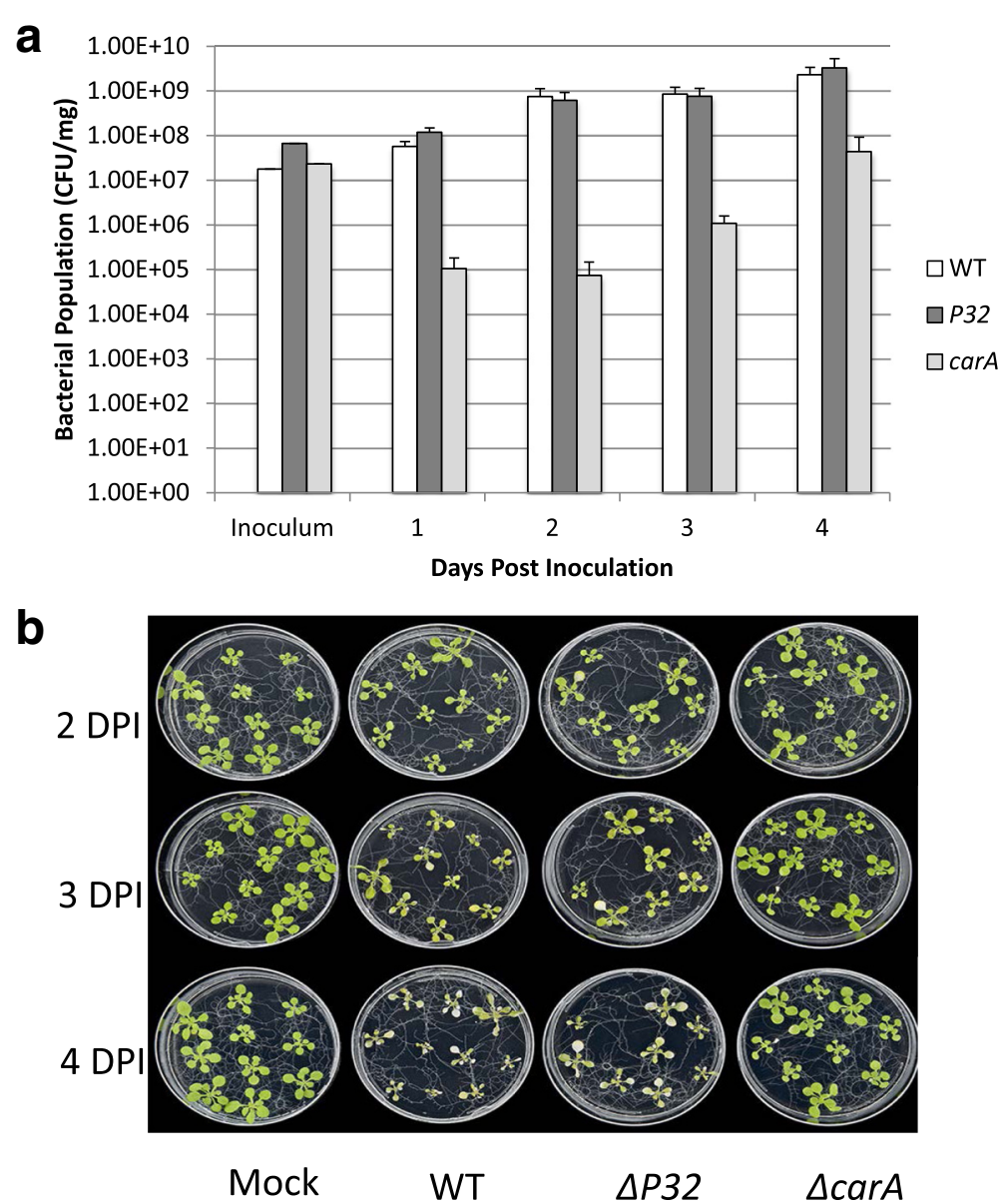

Fig. 7 carA contributes to fitness in Arabidopsis seedlings. a Arabidopsis seedlings were inoculated with suspensions containing $1 \times 10^{7}$ CFU $\mathrm{ml}^{-1}$ of $\mathrm{WT}, \triangle \mathrm{P} 32$, or $\triangle \mathrm{carA}$. At the time points shown, bacteria were extracted from leaves and plated on $\mathrm{KB}$ containing rifampicin for enumeration. The values shown are the average CFU/mg with standard deviation of three seedlings per strain. The experiment was repeated twice with similar results. $\mathbf{b}$ Disease phenotype of Arabidopsis seedlings flood-inoculated with a bacterial suspension of WT, $\triangle P 32$, or $\triangle$ carA. Mock-inoculated seedlings were flooded with sterile distilled $\mathrm{H}_{2} \mathrm{O}$ containing $0.025 \%$ Silwet L-77. Photographs were taken 2, 3, and 4 dpi

stem-loop structure [32]. The pyrimidine response is reduced when a portion of the right arm of the stemloop structure is deleted, and it is abolished when the stem-loop structure is completely removed. Since car $A B$ expression continues to be responsive to arginine levels in these experiments, the stem-loop structure appears to be required specifically for pyrimidine regulation of $\operatorname{car} A B$.

Our data shows that regulation of carAB in DC3000 resembles the regulation reported in $P$. aeruginosa. However there are some novel features. Although the qRT-PCR data suggests that ArgR represses the expression of P32 and carA, unexpectedly our promoter fusion data shows that addition of arginine to the medium increases the expression of P32 and carA in contrast to the repression observed in $P$. aeruginosa. However the regulation of the pyrimidine pathway in Pseudomonas is strongly influenced by pyrimidine and purine nucleotide effectors [46]. For example, the activity of the carbamoyl-phosphate synthase is inhibited by UMP and activated by ornithine and $\mathrm{N}$-acetylornithine [47] and $\operatorname{car} A B$ expression is subject to pyrimidine control via an attenuation mechanism. Therefore it is possible, that under the conditions we examined expression, the DC3000 cells are experiencing a high requirement for pyrimidines and expression of P32 and carA is not repressed upon supplementation of arginine. Additionally, the CPase of previously studied pseudomonads shows in most cases only limited repression by arginine and the ability of arginine to repress genes involved in arginine biosynthesis is sometimes influenced by carbon source [37]. Taken together our data indicates that the regulation of P32 and carA is complex in P. syringae and differs from the regulation observed in $P$. aeruginosa. More extensive analyses are needed to determine direct regulation by ArgR and further characterize possible posttranscriptional regulation that may be occurring in these pathways in P. syringae. 

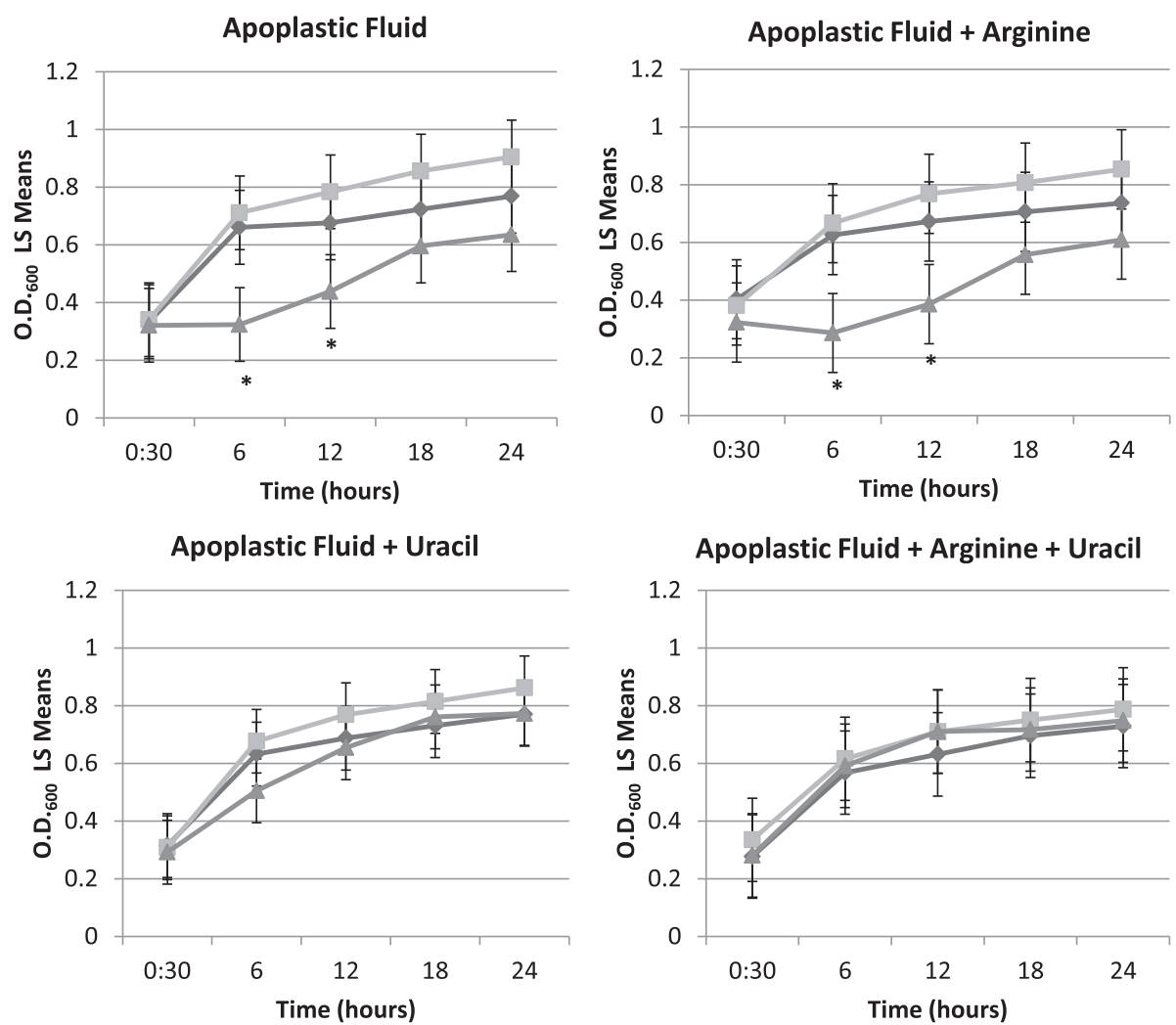

Fig. 8 CarA contributes to growth in apoplastic fluid. Growth of wild type DC3000 (dark gray diamonds), $\triangle P 32$ (light gray squares) and $\triangle$ carA (light grey triangles) in apoplastic fluid, apoplastic fluid supplemented with $40 \mathrm{mM}$ arginine or $10 \mathrm{mM}$ uracil, and apoplastic fluid supplemented with $40 \mathrm{mM}$ arginine and $10 \mathrm{mM}$ uracil. Growth is represented as least squares means (LS Means) with standard error of O.D.600 Over time. The data shown represent 3 biological replicates per strain, each with 3 technical replicates. Post hoc comparisons were performed using Tukey HSD $(a=0.05)$. For each time point, the values which are significantly different from wild-type are shown with an asterisk. Statistical analyses were performed using JMP Pro 11

Another difference we observed when compared to the $P$. aeruginosa is in the 5'UTR of carA. Our unpublished data of sRNAs found in P. syringae along with the mapping of the $3^{\prime}$ end in this study supports the notion that a small transcript is produced from the $5^{\prime} \mathrm{UTR}$ of carA. Interestingly, in $P$. aeruginosa a leader peptide is produced from the carA promoter region [32]. Inspection of the $P$. syringae DC3000 carA promoter region did not reveal a possible start codon that could give rise to a small peptide in this region (data not shown). Recently it was predicted that in P. syringae pv. phaseolicola 1448A carA is regulated by attenuation [48]. We hypothesize that in DC3000 P32 is generated by transcription attenuation. A sRNA derived from the 5'UTR of carA might act in trans to regulate expression of other genes. This concept was first described in E. coli [49]. Recent studies have shown that 5'UTRs of pathogenic bacteria can accumulate as stable RNA molecules [50] and are capable of acting in trans. Work in $L$. monocytogenes showed that several cis-acting riboswitches located in the $5^{\prime}$ UTRs of mRNAs produce small transcripts as the result of premature transcription and these target and regulate the expression of other mRNAs in trans [51]. The possibility that P32 may act in trans is intriguing. Since this sRNA is conserved among the Pseudomonads, this could add a new complexity to the regulation of arginine biosynthesis in the Pseudomonads and could identify regulatory links between arginine and other regulatory pathways in these bacteria.

We found that in $P$. syringae a carA mutant displays reduced growth in apoloplastic fluid and reduced fitness in planta. During a screen for DC3000 mutants that displayed reduced virulence, Brooks, D.M. et al. discovered that a mutant with a Tn5 insertion in the carA gene showed reduced virulence in A. thaliana [52]. Although the authors suggested that the inability of the mutant to multiply to high levels in $A$. thaliana leaves was likely because of limited nutrients in the apoplast of $A$. thaliana leaves, no further studies were performed. Interestingly our studies have shown that the growth defect of $\triangle c a r A$ could not be restored at 6 or $12 \mathrm{~h}$ with addition of arginine to apoplastic fluid. Surprisingly, growth of $\triangle c a r A$ at the earlier time points could be restored to 

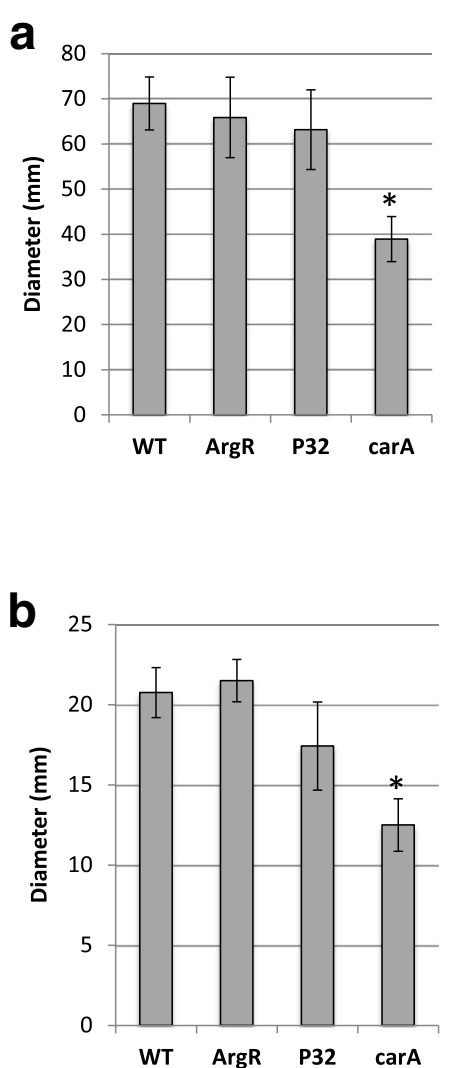

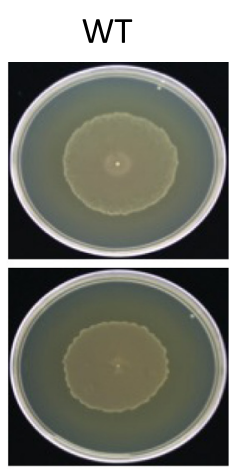

$\triangle P 32$

WT

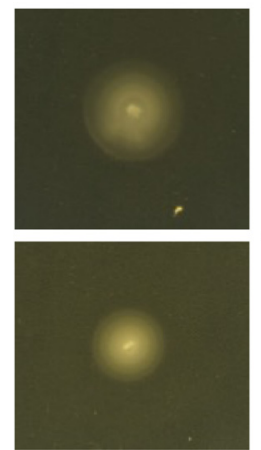

$\triangle P 32$

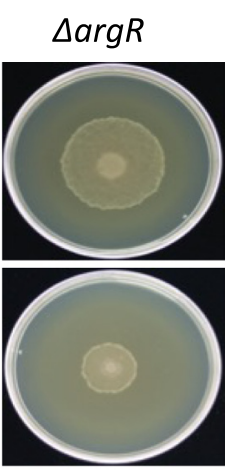

$\triangle c a r A$

$\triangle \arg R$

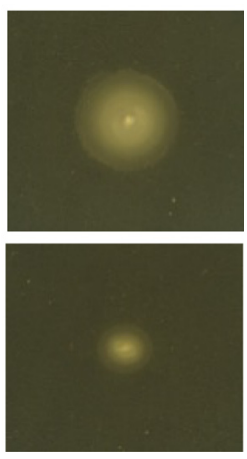

$\triangle$ carA

Fig. 9 Disruption of carA impairs motility. a Swarming of Pseudomonas syringae DC3000, $\triangle \arg R, \triangle \mathrm{P} 32$, and $\triangle$ carA after $24 \mathrm{~h}$. b Diameter of swimming colonies of Pseudomonas syringae DC3000, $\triangle \arg R, \triangle \mathrm{P} 32$, and $\triangle$ carA after $24 \mathrm{~h}$. The error bars represent the standard deviation of the mean. Data were analyzed by one-way analysis of variance (ANOVA) followed by Tukey HSD for pair-wise comparisons. Asterisks indicates significant difference for swarming (ANOVA, $P$-value $<0.004$ and Tukey HSD, $P$-values $<0.01)$ and swimming $(P$-value $<0.002$ using ANOVA; P-values <0.05 using Tukey HSD)

wild-type levels with the sole addition of uracil suggesting the supply of pyrimidines may be a limiting growth factor in apoplastic fluid. These data imply that there maybe sufficient arginine concentrations in planta but pyrimidines may be limiting thus resulting in reduced fitness in planta. Studies have shown that of the 20 protein amino acids, arginine was the only amino acid that could not be detected in apoplastic fluid [53]. To our knowledge the concentrations of pyrimidines in the tomato hosts have not been reported. It has been reported that Erwinia amylovora can obtain sufficient pyrimidines from host tissue to support growth and cause disease [54]. The situation we observe with $P$. syringae is more similar to the findings reported for some human bacterial pathogens, where de novo pyrimidine synthesis is required for growth in host-derived material [55].

The P32 mutant was able to grow to wild type levels in planta and in apoplastic fluid extracts. However, it caused reduced disease symptoms in tomato. Previous studies using DC3000 mutants have shown that reduced symptom formation is not always associated with reduced growth in planta [56]. The precise role of P32 in as yet undefined regulatory pathways that may lead to symptom production needs to be examined further.

The carA mutant formed better biofilms but was also compromised in its ability to swarm. Several mutants with insertions within genes involved in the pyrimidine nucleotide biosynthetic pathway and arginine metabolism displayed reduced biofilm formation [57, 58]. In $\mathrm{Vib}$ rio parahaemolyticus [59] a carA transposon mutant forms only thin pellicles at the air-medium interface. The involvement of carA in biofilm formation and swarming of $P$. syringae suggests that the reduced fitness in planta may be the result of multiple factors.

car $A B$ mutants of Pseudomonas spp. strain G are auxotrophic for arginine as well as pyrimidines but also deficient in several traits [34] such as extracellular polysaccharide production. Interestingly, the $\operatorname{car} A B$ genes from Pseudomonas sp. strain G are required for the degradation of diffusible signal factor (DSF), a fatty acid signal molecule involved in regulation of virulence in several Xanthomonas species as well as Xylella fastidiosa 


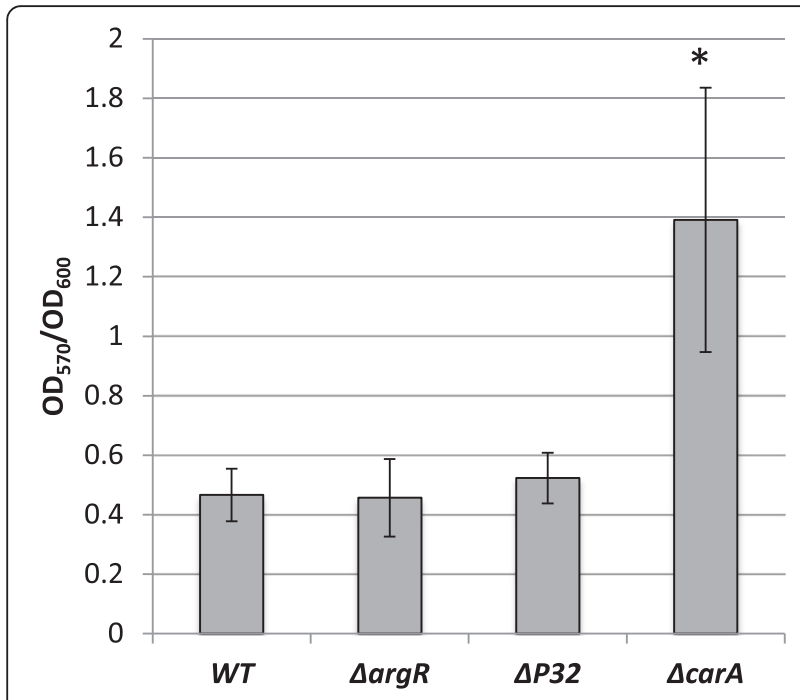

Fig. 10 Disruption of carA enhances biofilm formation. Biofilm formation by P. syringae DC3000, $\triangle \arg R, \triangle \mathrm{P} 32$, and $\triangle$ carA. Cells were grown for $72 \mathrm{~h}$ at $28^{\circ} \mathrm{C}$ in 96-well microtiter plates containing nutrient broth, and surface-associated biofilm formation was analyzed by crystal violet staining of the adherent biofilm, extraction of the crystal violet with acetic acid, and measurement of the absorbance $\left(\mathrm{OD}_{570}\right)$. All experiments were done in triplicate with at minimum of three technical repeats. Data were analyzed by one-way analysis of variance (ANOVA) followed by Tukey HSD for pair-wise comparisons. Asterisks indicate statistically significant difference $(P<0.003$ by ANOVA; $P<0.01$ using Tukey HSD)

[34]. Interestingly, a car $A B$ mutant strain of Halomonas eurihalina is also deficient in exopolysaccharide production [41]. This deficiency is thought to be a result of a decrease in the UDP-sugar pool. These compounds are essential to the synthesis of nucleotide di-phospho-sugar precursors such as UDP glucose and UDP galactose. UDP sugar is utilized in the synthesis not only of extracellular polysaccharides but also of lipopolysaccharides and the glycosylation of lipids and fatty acids. It is possible that the carA mutant of $P$. syringae displays altered production of extracellular polysaccharides. At least three exopolysaccharides (Psl, Pel, and alginate) contribute to biofilm formation in $P$. aeruginosa [60]. P. syringae DC3000 is able to produce Psl and alginate but does not encode for genes for the polysaccharide Pel [61]. Alterations in production of Psl can influence biofilm formation and swarming motility of $P$. aeruginosa [62]. Our future studies will explore if there is an involvement of carA in exopolysaccharide production in P. syringae.

\section{Conclusions}

In this study we found that carA of $P$. syringae plays an important role in providing arginine and uracil for growth of the bacterium and also influences other factors that are potentially important for growth and survival during infection. In conclusion, our data also show that carA is important for growth and survival of P. syringae in planta.

\section{Methods \\ Bacterial strains and growth conditions}

The bacterial strains and plasmids used in this study can be found in Additional file 2: Table S1. Pseudomonas syringae pv. tomato DC3000 (DC3000) was cultured at $28{ }^{\circ} \mathrm{C}$ or at room temperature on King's B (KB) agar [63]. Where noted, the minimal media used were MG Mannitol-Glutamate (MG) medium (10 g/L of mannitol, $2 \mathrm{~g} / \mathrm{L}$ of L-glutamic acid, $0.5 \mathrm{~g} / \mathrm{L}$ of $\mathrm{KH}_{2} \mathrm{PO}_{4}, 0.2 \mathrm{~g} / \mathrm{L}$ of $\mathrm{NaCl}, 0.2 \mathrm{~g} / \mathrm{L}$ of $\mathrm{MgSO}_{4}$, final $\mathrm{pH}$ of 7) [64] and VBMM [65]. When desired arginine and uracil were used at final concentrations of $40 \mathrm{mM}$ and $10 \mathrm{mM}$, respectively.

\section{Bacterial growth assays}

For evaluating growth, overnight cultures of each strain were prepared in liquid $\mathrm{KB}$ and incubated at $28^{\circ} \mathrm{C}$ with shaking. The next morning cultures were centrifuged and the pellets re-suspended in $1 \mathrm{~mL}$ of sterile water. The pellets were washed two more times and then resuspended in $1 \mathrm{~mL}$ of sterile water. Following resuspension, the $\mathrm{OD}_{600}$ of the cultures was measured, suspensions were diluted to $\mathrm{OD}_{600}=2.0$ in $1 \mathrm{~mL}$ of water, and the $\mathrm{OD}_{600}$ was measured again. The wells of a 96-well plate were filled with $200 \mu \mathrm{L}$ of appropriate medium and then inoculated with $20 \mu \mathrm{L}$ of bacterial suspension. Plates were incubated at $28.0{ }^{\circ} \mathrm{C}$ with shaking in a Biotek Synergy 2 microplate reader (Biotek, Winooski, VT). $\mathrm{OD}_{600}$ was measured every $30 \mathrm{~min}$ for $24 \mathrm{~h}$. Three wells were measured for each bacterial strain/medium. When necessary, medium was supplemented with arginine (final concentration of $40 \mathrm{mM}$ ) and/or uracil (final concentration of $10 \mathrm{mM}$ ). Growth curves were repeated three times. Growth at time points $6,12,18$ and $24 \mathrm{~h}$ was used for post-hoc statistical analysis. Statistical significance was assessed using Tukey HSD for pair-wise comparisons $(\alpha=0.05)$.

\section{Apoplastic fluid extraction and growth}

Apoplastic fluid was extracted from four-week old Solanum lycopersicum cv. MoneyMaker tomato plants following the protocol described in [53] with the following modifications. Whole leaves were removed and submerged in a container of DI water. The container was placed in a bell jar and a series of vacuum-pressure cycles were applied to the leaves at approximately $24 \mathrm{psi}$ until the leaves were fully infiltrated. The leaves were removed, blotted dry, and carefully rolled into a 5-mL syringe barrel. The syringe was placed in a $15-\mathrm{mL}$ conical vial and centrifuged at 2,000 rpm for $5 \mathrm{~min}$ at $4{ }^{\circ} \mathrm{C}$ to collect apoplastic fluid. Fluid was aliquoted into $1.5 \mathrm{~mL}$ microcentrifuge tubes and centrifuged again at 
$3,000 \mathrm{rpm}$ for $10 \mathrm{~min}$ at $4{ }^{\circ} \mathrm{C}$. The supernatant was removed and placed into a $1.5 \mathrm{~mL}$ microcentrifuge tube and stored at $-80{ }^{\circ} \mathrm{C}$. To test for cytoplasmic contamination, a fraction of the extracted apoplastic fluid was evaluated for Glucose-6-Phosphate Dehydrogenase (G6PDH) activity and compared to a leaf homogenate using a G6PDH Asssy Kit (Sigma-Aldrich, St. Louis, MO) according to the manufacturer's instructions. Only apoplastic fluid that had little to no cytoplasmic contamination was used in growth analysis. Growth was evaluated using the protocol described above for bacterial growth assays. Three biological replicates were performed per strain, each with three technical replicates. Statistical significance was assessed using Tukey HSD $(\alpha=0.05)$.

\section{Creation of reporter constructs}

Genomic regions upstream of carA (PSPTO_4502) were amplified via PCR using chromosomal DNA isolated from wild-type DC3000. Primers 94 and 95 were designed to amplify the entire region between $\operatorname{dapB}$ (PSPTO_4503) and carA (PSPTO_4502) for a total product length of $228 \mathrm{bp}$. Primers 94 and 97 yielded a product of $187 \mathrm{bp}$ in length that disrupted the putative stem loop region. Primers 94 and 98 amplified a region upstream of $P 32$ (143 bp). The $117 \mathrm{bp}$ product obtained using primers 99 and 95 lacks the putative promoter upstream of P32. Primers 100 and 95 amplified a region of 51 bases upstream of carA that does not include P32. These amplified regions were cloned by PCR and TOPO cloning using the pENTR/D-TOPO vector (Invitrogen, Carlsbad CA). Positive clones were selected by plating on LB supplemented with $50 \mu \mathrm{g} / \mathrm{ml}$ of kanamycin. Inserts were then sequenced (Biotechnology Resource Center (BRC) at Cornell University) to identify correct clones. LR cloning and the Gateway ${ }^{\circ}$ LR Clonase ${ }^{\circ}$ II Enzyme mix (Invitrogen) were used to move the promoter regions into the destination vector pBS58, which contains a promoterless lux operon [66, 67]. The LR mixture was transformed into One Shot Omni-Mach 2 T1 cells (Invitrogen). Positive clones were selected by plating on LB supplemented with $50 \mu \mathrm{g} / \mathrm{ml}$ of kanamycin and $10 \mu \mathrm{g} / \mathrm{ml}$ of tetracycline and subsequently confirmed by sequencing.

\section{Promoter fusion assays}

Promoter fusion constructs were introduced into the appropriate $P$. syringae strains using electroporation and plating transformants on $\mathrm{KB}$ plates containing kanamycin. Overnight cultures were prepared in $\mathrm{KB}$ medium supplemented with kanamycin and incubated at $28.0{ }^{\circ} \mathrm{C}$ with shaking then diluted the next day to an $\mathrm{OD}_{600}=0.1$ in VBMM or VBMM supplemented with $40 \mathrm{mM}$ arginine and/or $10 \mathrm{mM}$ uracil. $200 \mu \mathrm{L}$ of the culture was dispensed into individual wells of a 96 well plate in a
Biotek Syngery 2 microplate reader. The cultures were incubated at $28.0{ }^{\circ} \mathrm{C}$ with shaking. $\mathrm{OD}_{600}$ and relative luminescence were measured every $2 \mathrm{~h}$ and relative luminescence calculated as luminescence/ $\mathrm{OD}_{600}$. The experiment was performed at least three times. Statistical significance was assessed using Tukey HSD $(\alpha=0.05)$.

\section{RNA isolation}

Total RNA was prepared using Trizol (Invitrogen) following the manufacturer's instructions. Once isolated, RNA was treated with DNAse (Ambion, Austin, TX) to remove residual DNA. RNA was extracted using phenol:chloroform: IAA (isoamyl alcohol) then cleaned and concentrated using RNA Clean-up \& Concentrator kit (Zymo Research, Irvine, CA). Removal of DNA was verified by quantitative real-time $\mathrm{PCR}$ with primers to the normalizing genes gap 1 (PSPTO_1287) or gyrA (PSPTO_1745) [68].

\section{Reverse transcription-PCR (RT-PCR)}

Total RNA (100 ng) was reverse transcribed using Superscript III (Invitrogen) and primers listed in Additional file 2: Table S1 according to the manufacturer's instructions. PCR reactions were performed for $30 \mathrm{cy}$ cles. The PCR products were separated by agarose gel electrophoresis.

\section{3' rapid amplification of CDNA ends (RACE)}

3' RACE was performed as described by Moll et al. [69]. This protocol was adapted from Argaman et al. [70].

\section{Quantitative real-time PCR (qPCR)}

qPCR was performed as described by Park et al. [71]. Extracted RNA was synthesized into cDNA using the qScript cDNA Supermix (Quanta Biosciences, Gaithersburg, MD) and qPCR was performed using IQ SYBR green Supermix (Bio-Rad, Hercules, CA) on a iQ5 multicolor real-time detection system (BioRad). The production of nonspecific products was determined by the dissociation protocol included in the software provided with the machine. All primer pairs were found to yield unique products using the dissociation protocol (data not shown). The PCR assay was carried out as previously described [71]. Gene expression fold-change was calculated using the $\Delta \Delta C_{t}$ method. $C_{t}$ values of each gene tested were normalized to the $\mathrm{C}_{\mathrm{t}}$ values of the housekeeping gene gap1 (PSPTO_1287). Primers used for qRT-PCR are listed in Additional file 2: Table S1.

\section{Construction of mutant strains}

Primers used for the construction of mutant strains are listed in Additional file 2: Table S1. Unmarked deletion strains were constructed using pK18mobsacB plasmid [72]. DNA fragments of approximately $1.0 \mathrm{~kb}$ upstream and downstream of $P 32$, $\operatorname{carA}$, and $\operatorname{argR}$ were amplified 
by PCR, gel purified and then joined by splicing by overlap extension PCR. The P32, carA, and $\operatorname{argR}$ genes were then deleted from DC3000 using the deletion constructs and marker exchange mutagenesis [71]. Mutant clones (those containing the deletion) were confirmed by DNA sequencing.

\section{Complementation of $\triangle c a r A$}

The coding region of carA along with its native Shine Dalgarno sequence was amplified from DC3000 genomic DNA using oligos SCMF3 F and SCMF4 R and the Expand High Fidelity PCR System from Roche. The primers contained the restriction enzyme site $\mathrm{XbaI}$ at their $5^{\prime}$ ends. The XbaI-digested PCR product was cloned into the $\mathrm{XbaI}$ site of broad host range vector pUCP22 containing the lac promoter [73], and sequenced to confirm the presence of carA. The resulting plasmid was designated as pUCP22::carA.pUCP22::carA was electroporated into DC3000 $\triangle$ carA to generate the complementation strain of $\triangle$ carA. For controls, pUCP22 was electroporated into DC3000 and $\triangle$ carA. The strains were selected on gentamycin at $5 \mu \mathrm{g} / \mathrm{ml}$. Bacterial growth assays were performed as described above.

\section{Evaluating virulence in Arabidopsis plant seedlings}

To assess virulence, the Arabidopsis seedling floodinoculation assay was used [74] following the modifications described in Park et al. [71].

\section{Tomato Dip-inoculation}

Tomato dip inoculations were performed as described by Park et al. [71].

\section{Motility assays}

P. syringae strains were grown overnight at $28{ }^{\circ} \mathrm{C}$ in $\mathrm{KB}$. Overnight cultures were diluted to $\mathrm{OD}_{600}$ of $\sim 0.3$ and $5 \mu$ were used to spot onto swarming plates or stab onto swimming plates. Swarming plates consisted of nutrient broth $(8 \mathrm{~g} / \mathrm{L})$ and $0.5 \%$ (wt/vol) agar. Swimming assays were performed using nutrient broth $(8 \mathrm{~g} / \mathrm{L})$ and $0.3 \%$ (wt/vol) agar. Swarm and swim zones were measured after plates were incubated for $24 \mathrm{~h}$ at room temperature. Three technical replicates were performed for each experiment and each experiment was performed three times. Data were analyzed by one-way analysis of variance (ANOVA) followed by Tukey HSD for pairwise comparisons.

\section{Biofilm formation}

P. syringae strains were grown overnight at $28{ }^{\circ} \mathrm{C}$ in $\mathrm{KB}$. Overnight cultures were washed three times with nutrient broth and diluted to $\mathrm{OD}_{600}$ of 1.0. Cultures were added to 96-well plates pre-filled with media to final $\mathrm{OD}_{600}$ of 0.1 and allowed to incubate at $28{ }^{\circ} \mathrm{C}$ for $72 \mathrm{~h}$ under static conditions. After $72 \mathrm{~h}$ of incubation the $\mathrm{OD}_{600}$ was measured and media was removed from each well. Biofilm formation was assessed based on protocols described by Merritt et al. [75] and O'Toole et al. [76]. Approximately $250 \mu \mathrm{l}$ of $0.1 \%$ crystal violet stain was added to each well and allowed to incubate for $5 \mathrm{~min}$. The stain was removed and wells were washed three times with $\mathrm{ddH}_{2} \mathrm{O}$. The stained biofilms were resuspended in $30 \%$ acetic acid and $\mathrm{OD}_{570}$ was recorded for each well. Four replicates of each strain were normalized using the final $\mathrm{OD}_{600}$, averaged, and standard deviation was computed. Statistical significance was assessed using a one-way ANOVA test followed by Tukey HSD for pair-wise comparisons.

\section{Additional files}

Additional file 1: Figure S1. Expression of carA in the $P 32$ mutant. Figure $\mathbf{S 2}$ Growth of the complemented mutant of $\triangle$ carA is comparable to wild type DC3000. (PDF $167 \mathrm{~kb}$ )

Additional file 2: Table S1. List of plasmids, strains, and primers. (PDF $96 \mathrm{~kb}$ )

\section{Acknowledgments}

We would like to thank Samuel Cartinhour for helpful discussions and editorial suggestions. We would also like to thank Zhongmeng Bao for contributing to the design of the P32 mutant and performing the $3^{\prime} R A C E$, Zoe Anderson for preliminary qRT-PCR results, and Janet Wilson for preliminary analysis of the mutants in the plant seedling assay. We thank Lynn Johnson, Cornell Statistical Consulting Unit, for help with post-hoc analysis of data.

The U.S. Department of Agriculture (USDA) is an equal opportunity provider and employer. Mention of trade names or commercial products in this publication is solely for the purposes of providing specific information and does not imply recommendation or endorsement by the USDA.

\section{Funding}

This work was supported by the USDA-ARS CRIS project 8062-2100-035-00D, "Pseudomonas Systems Biology".

\section{Availability of data and materials}

All data generated or analyzed during this study are included in this published article and its supplementary information files.

\section{Authors' contributions}

$\mathrm{BB}$ and MF conceived the project. BB, SC, KD, KS, MF designed and performed the experiments. $\mathrm{BB}, \mathrm{SC}$ and MF contributed to the experimental design and data analyses. BB, SC, KD, and MF wrote the manuscript. Statistical analyses were performed by SC. All authors read and approved the final manuscript.

\section{Competing interests}

The authors declare that they have no competing interests.

\section{Consent for publication}

Not applicable.

Ethics approval and consent to participate Not applicable.

\section{Author details}

${ }^{1}$ School of Integrative Plant Science, Section of Plant Pathology and Plant-Microbe Biology, Cornell University, Ithaca, NY, USA. ${ }^{2}$ Emerging Pests and Pathogens Research Unit, Robert W. Holley Center for Agriculture and Health, Agricultural Research Service, United States Department of 
Agriculture, Ithaca, NY, USA. ${ }^{3}$ Department of Health Promotion and Physical Education, School of Health Sciences and Human Performance, Ithaca College, Ithaca, NY, USA. ${ }^{4}$ Present Address: Cornell Lab of Ornithology, Cornell University, 159 Sapsucker Woods Rd, Ithaca, NY, USA.

\section{Received: 6 May 2016 Accepted: 19 August 2016}

Published online: 24 August 2016

\section{References}

1. Xin XF, He SY. Pseudomonas syringae pv. tomato DC3000: a model pathogen for probing disease susceptibility and hormone signaling in plants. Annu Rev Phytopathol. 2013;51:473-98.

2. Lindeberg M, Cunnac S, Collmer A. Pseudomonas syringae type III effector repertoires: last words in endless arguments. Trends Microbiol. 2012;20(4):199-208.

3. de Bruijn I, de Kock MJ, Yang M, de Waard P, van Beek TA, Raaijmakers JM Genome-based discovery, structure prediction and functional analysis of cyclic lipopeptide antibiotics in Pseudomonas species. Mol Microbiol. 2007; 63(2):417-28.

4. Arrebola E, Cazorla FM, Perez-Garcia A, de Vicente A. Chemical and metabolic aspects of antimetabolite toxins produced by Pseudomonas syringae pathovars. Toxins (Basel). 2011;3(9):1089-110.

5. Gutierrez-Barranquero JA, Carrion VJ, Murillo J, Arrebola E, Arnold DL, Cazorla FM, de Vicente A. A Pseudomonas syringae diversity survey reveals a differentiated phylotype of the pathovar syringae associated with the mango host and mangotoxin production. Phytopathology. 2013;103(11):1115-29.

6. Payne SM. Iron acquisition in microbial pathogenesis. Trends Microbiol. 1993;1(2):66-9

7. Boch J, Joardar V, Gao L, Robertson TL, Lim M, Kunkel BN. Identification of Pseudomonas syringae pv. tomato genes induced during infection of Arabidopsis thaliana. Mol Microbiol. 2002;44(1):73-88.

8. Brown DG, Allen C. Ralstonia solanacearum genes induced during growth in tomato: an inside view of bacterial wilt. Mol Microbiol. 2004;53(6):1641-60.

9. Marco ML, Legac J, Lindow SE. Conditional survival as a selection strategy to identify plant-inducible genes of Pseudomonas syringae. Appl Environ Microbiol. 2003;69(10):5793-801.

10. Marco ML, Legac J, Lindow SE. Pseudomonas syringae genes induced during colonization of leaf surfaces. Environ Microbiol. 2005;7(9):1379-91.

11. Osbourn AE, Barber CE, Daniels MJ. Identification of plant-induced genes of the bacterial pathogen Xanthomonas campestris pathovar campestris using a promoter-probe plasmid. EMBO J. 1987;6(1):23-8.

12. Ramos-Gonzalez MI, Campos MJ, Ramos JL. Analysis of Pseudomonas putida KT2440 gene expression in the maize rhizosphere: in vivo [corrected] expression technology capture and identification of root-activated promoters. J Bacteriol. 2005;187(12):4033-41.

13. Silby MW, Levy SB. Use of in vivo expression technology to identify genes important in growth and survival of Pseudomonas fluorescens Pf0-1 in soil: discovery of expressed sequences with novel genetic organization. J Bacteriol. 2004;186(21):7411-9.

14. Yang S, Perna NT, Cooksey DA, Okinaka Y, Lindow SE, Ibekwe AM, Keen NT, Yang $\mathrm{CH}$. Genome-wide identification of plant-upregulated genes of Erwinia chrysanthemi 3937 using a GFP-based IVET leaf array. Mol Plant Microbe Interact. 2004;17(9):999-1008.

15. Zhao Y, Blumer SE, Sundin GW. Identification of Erwinia amylovora genes induced during infection of immature pear tissue. J Bacteriol. 2005;187(23):8088-103.

16. Hartmann T, Baronian G, Nippe N, Voss M, Schulthess B, Wolz C, Eisenbeis J, Schmidt-Hohagen K, Gaupp R, Sunderkotter C, et al. The catabolite control protein $\mathrm{E}$ (CcpE) affects virulence determinant production and pathogenesis of Staphylococcus aureus. J Biol Chem. 2014;289:29701-11.

17. Palace SG, Proulx MK, Lu S, Baker RE, Goguen JD. Genome-Wide Mutant Fitness Profiling Identifies Nutritional Requirements for Optimal Growth of Yersinia pestis in Deep Tissue. MBio. 2014;5(4). doi:10.1128/mBio.01385-14.

18. Schoen C, Kischkies L, Elias J, Ampattu BJ. Metabolism and virulence in Neisseria meningitidis. Front Cell Infect Microbiol. 2014;4:114

19. Bucker R, Heroven AK, Becker J, Dersch P, Wittmann C. The pyruvate tricarboxylic acid cycle node: a focal point of virulence control in the enteric pathogen Yersinia pseudotuberculosis. J Biol Chem. 2014;289:30114-32.

20. Papenfort $K$, Vogel J. Small RNA functions in carbon metabolism and virulence of enteric pathogens. Front Cell Infect Microbiol. 2014;4:91.
21. Lucchetti-Miganeh C, Burrowes E, Baysse C, Ermel G. The post-transcriptional regulator CsrA plays a central role in the adaptation of bacterial pathogens to different stages of infection in animal hosts. Microbiology. 2008;154(Pt 1):16-29.

22. Wang L, Beer SV. Application of signature-tagged mutagenesis to the study of virulence of Erwinia amylovora. FEMS Microbiol Lett. 2006;265(2):164-71.

23. Matas IM, Lambertsen L, Rodriguez-Moreno L, Ramos C. Identification of novel virulence genes and metabolic pathways required for full fitness of Pseudomonas savastanoi pv. savastanoi in olive (Olea europaea) knots. New Phytol. 2012;196(4):1182-96.

24. Hovel-Miner G, Faucher SP, Charpentier X, Shuman HA. ArgR-regulated genes are derepressed in the Legionella-containing vacuole. J Bacteriol. 2010;192(17):4504-16.

25. Ryan S, Begley M, Gahan CG, Hill C. Molecular characterization of the arginine deiminase system in Listeria monocytogenes: regulation and role in acid tolerance. Environ Microbiol. 2009;11(2):432-45.

26. Sassetti CM, Rubin EJ. Genetic requirements for mycobacterial survival during infection. Proc Natl Acad Sci U S A. 2003;100(22):12989-94.

27. Talaue MT, Venketaraman V, Hazbon MH, Peteroy-Kelly M, Seth A, Colangeli R, Alland D, Connell ND. Arginine homeostasis in J774.1 macrophages in the context of Mycobacterium bovis BCG infection. J Bacteriol. 2006;188(13):4830-40.

28. Ramos LS, Lehman BL, Peter KA, McNellis TW. Mutation of the Erwinia amylovora argD gene causes arginine auxotrophy, non-pathogenicity in apple and reduced virulence in pear. Appl Environ Microbiol. 2014;80:6739-49.

29. Livny J, Brencic A, Lory S, Waldor MK. Identification of 17 Pseudomonas aeruginosa sRNAs and prediction of sRNA-encoding genes in 10 diverse pathogens using the bioinformatic tool sRNAPredict2. Nucleic Acids Res. 2006;34(12):3484-93.

30. Filiatrault MJ, Stodghill PV, Myers CR, Bronstein PA, Butcher BG, Lam H, Grills G, Schweitzer P, Wang W, Schneider DJ, et al. Genome-wide identification of transcriptional start sites in the plant pathogen Pseudomonas syringae pv. tomato str. DC3000. PLoS One. 2011;6(12):e29335.

31. Filiatrault MJ, Stodghill PV, Bronstein PA, Moll S, Lindeberg M, Grills G, Schweitzer P, Wang W, Schroth GP, Luo S, et al. Transcriptome analysis of Pseudomonas syringae identifies new genes, noncoding RNAs, and antisense activity. J Bacteriol. 2010;192(9):2359-72.

32. Kwon DH, Lu CD, Walthall DA, Brown TM, Houghton JE, Abdelal AT. Structure and regulation of the carAB operon in Pseudomonas aeruginosa and Pseudomonas stutzeri: no untranslated region exists. J Bacteriol. 1994; 176(9):2532-42

33. Park SM, Lu CD, Abdelal AT. Purification and characterization of an arginine regulatory protein, ArgR, from Pseudomonas aeruginosa and its interactions with the control regions for the car, argF, and aru operons. J Bacteriol. 1997; 179(17):5309-17.

34. Newman KL, Chatterjee S, Ho KA, Lindow SE. Virulence of plant pathogenic bacteria attenuated by degradation of fatty acid cell-to-cell signaling factors. Mol Plant Microbe Interact. 2008:21(3):326-34.

35. Guo J, Song X, Zou L-f, Zou H-s, Chen G-y. The small and large subunits of carbamoyl-phosphate synthase exhibit diverse contributions to pathogenicity in Xanthomonas citri subsp. citri. J Integr Agric. 2015;14(7):1338-47.

36. Zhuo T, Rou W, Song X, Guo J, Fan X, Kamau GG, Zou H. Molecular study on the $C a r A B$ operon reveals that $c a r B$ gene is required for swimming and biofilm formation in Xanthomonas citri subsp. citri. BMC Microbiol. 2015;15:225.

37. Cunin R, Glansdorff N, Pierard A, Stalon V. Biosynthesis and metabolism of arginine in bacteria. Microbiol Rev. 1986;50(3):314-52.

38. Arioli S, Monnet C, Guglielmetti S, Mora D. Carbamoylphosphate synthetase activity is essential for the optimal growth of Streptococcus thermophilus in milk. J Appl Microbiol. 2009;107(1):348-54.

39. Vaishnav P, Randev S, Jatiani S, Aggarwal S, Keharia H, Vyas PR, Nareshkumar G, Archana G. Characterization of carbamoyl phosphate synthetase of Streptomyces spp. Indian J Exp Biol. 2000;38(9):931-5.

40. Haas D, Holloway BW, Schambock A, Leisinger T. The genetic organization of arginine biosynthesis in Pseudomonas aeruginosa. Mol Gen Genet. 1977;154(1):7-22.

41. Llamas I, Suarez A, Quesada E, Bejar V, del Moral A. Identification and characterization of the car $A B$ genes responsible for encoding carbamoylphosphate synthetase in Halomonas eurihalina. Extremophiles. 2003;7(3):205-11.

42. Lu CD, Yang Z, Li W. Transcriptome analysis of the ArgR regulon in Pseudomonas aeruginosa. J Bacteriol. 2004;186(12):3855-61. 
43. Kim W, Surette MG. Metabolic differentiation in actively swarming salmonella. Mol Microbiol. 2004;54(3):702-14.

44. OToole GA. Microtiter dish biofilm formation assay. J Vis Exp. 2011;(47). doi: $10.3791 / 2437$

45. Turnbough Jr CL, Switzer RL. Regulation of pyrimidine biosynthetic gene expression in bacteria: repression without repressors. Microbiol Mol Biol Rev. 2008;72(2):266-300. table of contents.

46. Chu CP, West TP. Pyrimidine biosynthetic pathway of Pseudomonas fluorescens. J Gen Microbiol. 1990;136(5):875-80.

47. Abdelal AT, Bussey L, Vickers L. Carbamoylphosphate synthetase from Pseudomonas aeruginosa. Subunit composition, kinetic analysis and regulation. Eur J Biochem. 1983;129(3):697-702.

48. Naville M, Gautheret D. Premature terminator analysis sheds light on a hidden world of bacterial transcriptional attenuation. Genome Biol. 2010;11(9):R97.

49. Vogel J, Bartels V, Tang TH, Churakov G, Slagter-Jager JG, Huttenhofer A, Wagner EG. RNomics in Escherichia coli detects new sRNA species and indicates parallel transcriptional output in bacteria. Nucleic Acids Res. 2003; 31(22):6435-43.

50. Sharma CM, Hoffmann S, Darfeuille F, Reignier J, Findeiss S, Sittka A, Chabas S, Reiche K, Hackermuller J, Reinhardt R, et al. The primary transcriptome of the major human pathogen Helicobacter pylori. Nature. 2010;464(7286):250-5.

51. Loh E, Dussurget O, Gripenland J, Vaitkevicius K, Tiensuu T, Mandin P, Repoila F, Buchrieser C, Cossart P, Johansson J. A trans-acting riboswitch controls expression of the virulence regulator PrfA in Listeria monocytogenes. Cell. 2009;139(4):770-9.

52. Brooks DM, Hernandez-Guzman G, Kloek AP, Alarcon-Chaidez F, Sreedharan A, Rangaswamy V, Penaloza-Vazquez A, Bender CL, Kunkel BN. Identification and characterization of a well-defined series of coronatine biosynthetic mutants of Pseudomonas syringae pv. tomato DC3000. Mol Plant Microbe Interact. 2004;17(2):162-74.

53. Rico A, Preston GM. Pseudomonas syringae pv. tomato DC3000 uses constitutive and apoplast-induced nutrient assimilation pathways to catabolize nutrients that are abundant in the tomato apoplast. Mol Plant Microbe Interact. 2008;21(2):269-82.

54. Ramos LS, Sinn JP, Lehman BL, Pfeufer EE, Peter KA, McNellis TW. Erwinia amylovora pyrC mutant causes fire blight despite pyrimidine auxotrophy. Lett Appl Microbiol. 2015;60(6):572-9.

55. Samant S, Lee H, Ghassemi M, Chen J, Cook JL, Mankin AS, Neyfakh AA. Nucleotide biosynthesis is critical for growth of bacteria in human blood. PLoS Pathog. 2008;4(2):e37.

56. Munkvold KR, Russell AB, Kvitko BH, Collmer A. Pseudomonas syringae pv. tomato DC3000 type III effector HopAA1-1 functions redundantly with chlorosis-promoting factor PSPTO4723 to produce bacterial speck lesions in host tomato. Mol Plant Microbe Interact. 2009;22(11):1341-55.

57. Musken M, Di Fiore S, Dotsch A, Fischer R, Haussler S. Genetic determinants of Pseudomonas aeruginosa biofilm establishment. Microbiology. 2010;156(Pt 2):431-41.

58. Ueda A, Attila C, Whiteley M, Wood TK. Uracil influences quorum sensing and biofilm formation in Pseudomonas aeruginosa and fluorouracil is an antagonist. Microb Biotechnol. 2009;2(1):62-74.

59. Enos-Berlage JL, Guvener ZT, Keenan CE, McCarter LL. Genetic determinants of biofilm development of opaque and translucent Vibrio parahaemolyticus. Mol Microbiol. 2005;55(4):1160-82.

60. Wei Q, Ma LZ. Biofilm matrix and its regulation in Pseudomonas aeruginosa. Int J Mol Sci. 2013;14(10):20983-1005.

61. Buell CR, Joardar V, Lindeberg M, Selengut J, Paulsen IT, Gwinn ML, Dodson RJ, Deboy RT, Durkin AS, Kolonay JF, et al. The complete genome sequence of the Arabidopsis and tomato pathogen Pseudomonas syringae pv. tomato DC3000. Proc Natl Acad Sci U S A. 2003;100(18):10181-6.

62. Wang S, Yu S, Zhang Z, Wei Q, Yan L, Ai G, Liu H, Ma LZ. Coordination of swarming motility, biosurfactant synthesis, and biofilm matrix exopolysaccharide production in Pseudomonas aeruginosa. Appl Environ Microbiol. 2014;80(21):6724-32.

63. King EO, Ward MK, Raney DE. Two simple media for the demonstration of pyocyanin and fluorescin. J Lab Clin Med. 1954;44(2):301-7.

64. Keane PJ, Kerr A, New PB. Crown Gall of Stone Fruit .2. Identification and Nomenclature of Agrobacterium Isolates. Australian J Biol Sci. 1970; 23(3):585-\&.

65. Schweizer HP. The agmR gene, an environmentally responsive gene, complements defective glpR, which encodes the putative activator for glycerol metabolism in Pseudomonas aeruginosa. J Bacteriol. 1991;173(21):6798-806.
66. Markel E, Maciak C, Butcher BG, Myers CR, Stodghill P, Bao Z, Cartinhour S, Swingle B. An extracytoplasmic function sigma factor-mediated cell surface signaling system in Pseudomonas syringae pv. tomato DC3000 regulates gene expression in response to heterologous siderophores. J Bacteriol. 2011;193(20):5775-83.

67. Swingle B, Thete D, Moll M, Myers CR, Schneider DJ, Cartinhour S. Characterization of the PvdS-regulated promoter motif in Pseudomonas syringae pv. tomato DC3000 reveals regulon members and insights regarding PvdS function in other pseudomonads. Mol Microbiol. 2008;68(4):871-89.

68. Vencato M, Tian F, Alfano JR, Buell CR, Cartinhour S, DeClerck GA, Guttman DS, Stavrinides J, Joardar V, Lindeberg $M$, et al. Bioinformatics-enabled identification of the HrpL regulon and type III secretion system effector proteins of Pseudomonas syringae pv. phaseolicola 1448A. Mol Plant Microbe Interact. 2006;19(11):1193-206.

69. Moll S, Schneider DJ, Stodghill P, Myers CR, Cartinhour SW, Filiatrault MJ. Contruction of an rsmX co-variance model and identification of five rsmX non-coding RNAs in Pseudomonas syringae pv. tomato DC3000. RNA Biol. 2010;7(5):1-9.

70. Argaman L, Hershberg R, Vogel J, Bejerano G, Wagner EG, Margalit H, Altuvia S. Novel small RNA-encoding genes in the intergenic regions of Escherichia coli. Curr Biol. 2001;11(12):941-50.

71. Park SH, Butcher BG, Anderson Z, Pellegrini N, Bao Z, D'Amico K, Filiatrault MJ. Analysis of the small RNA P16/RgsA in the plant pathogen Pseudomonas syringae pv. tomato strain DC3000. Microbiology. 2013;159(Pt 2):296-306.

72. Schafer A, Tauch A, Jager W, Kalinowski J, Thierbach G, Puhler A. Small mobilizable multi-purpose cloning vectors derived from the Escherichia coli plasmids pK18 and pK19: selection of defined deletions in the chromosome of Corynebacterium glutamicum. Gene. 1994;145(1):69-73.

73. West SE, Schweizer HP, Dall C, Sample AK, Runyen-Janecky LJ. Construction of improved Escherichia-Pseudomonas shuttle vectors derived from pUC18/ 19 and sequence of the region required for their replication in Pseudomonas aeruginosa. Gene. 1994;148(1):81-6.

74. Ishiga Y, Ishiga T, Uppalapati SR, Mysore KS. Arabidopsis seedling floodinoculation technique: a rapid and reliable assay for studying plant-bacterial interactions. Plant Methods. 2011;7:32

75. Merritt JH, Kadouri DE, OToole GA. Growing and analyzing static biofilms. Curr Protoc Microbiol. 2005; Chapter 1:Unit 1B.1.doi:10.1002/9780471729259. mc01b01s00.

76. OToole GA, Pratt LA, Watnick PI, Newman DK, Weaver VB, Kolter R. Genetic approaches to study of biofilms. Methods Enzymol. 1999;310:91-109.

\section{Submit your next manuscript to BioMed Central and we will help you at every step:}

- We accept pre-submission inquiries

- Our selector tool helps you to find the most relevant journal

- We provide round the clock customer support

- Convenient online submission

- Thorough peer review

- Inclusion in PubMed and all major indexing services

- Maximum visibility for your research

Submit your manuscript at www.biomedcentral.com/submit
( Biomed Central 